\title{
CrystEngComm
}

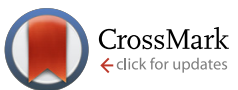

Cite this: CrystEngComm, 2015, 17, 4475

Received 20th April 2015, Accepted 14th May 2015

DOI: $10.1039 / c 5 c e 00771 b$

www.rsc.org/crystengcomm

\section{Establishing trends based on solvent system changes in cocrystals containing pyrogallol[4] arenes and fluorescent probes rhodamine B and pyronin $\mathrm{Y} \dagger$}

\author{
Constance R. Pfeiffer, Drew A. Fowler and Jerry L. Atwood*
}

\begin{abstract}
Cocrystal systems containing pyrogallol[4]arene molecules of various aliphatic tail lengths, the fluorescent probe rhodamine B, and a variety of solvents are examined and discussed. Additionally, two pyronin $Y$ cocrystals of C-methylpyrogallol[4]arene in methanol and C-ethylpyrogallol[4]arene in ethanol are crystallized and analyzed. For both the pyronin $Y$ and rhodamine $B$ cocrystals, solvent and aliphatic chain length have an effect on the packing, bowl shape of the pyrogallol[4]arene, probe complexation, and hydrogen bonding schemes. With pyronin $Y$ cocrystals of $C$-methylpyrogallol[4]arene form a tube-like structure, with pyronin $Y$ molecules in the centre of the tube while cocrystals of $C$-ethylpryogallol[4]arene form a bilayer-type structure.
\end{abstract}

\section{Introduction}

Pyrogallol[4]arenes are important building blocks for supramolecular complexes. The molecule consists of four aromatic groups arranged into a bowl shape and adorned with twelve hydroxyl groups on the upper-rim. Four aliphatic tail groups reside on the bridging aldehyde residues. Pyrogallol[4]arenes have the ability to form numerous architectures such as dimers, hexamers, nanotubes, and nanocages. Such structures have potential applications as catalysts and molecular transporters. ${ }^{1}$ Dimeric and hexameric pyrogallol[4]arenes may be formed by hydrogen bonding or by metal ions such as $\mathrm{Mn}^{2+}, \mathrm{Co}^{2+}, \mathrm{Ni}^{2+}, \mathrm{Cu}^{2+}$, or $\mathrm{Zn}^{2+} .2$ Additionally, because of their ability to act as a host, various types of guest molecules such as small inorganic molecules, pharmaceutical molecules, and ionic liquids have been cocrystallized with pyrogallol[4] arenes. $^{3-5}$

Fluorescent probe molecules have also been cocrystallized with pyrogallol[4]arenes. ${ }^{6} \quad C$-hexylpyrogallol[4]arene $\left(\mathrm{PgC}_{6}\right)$ has been cocrystallized with both pyrene butyric acid (PBA) and 1-(9-anthryl)-3-(4-dimethylaniline) propane (ADMA) in acetonitrile. Additionally, C-propan-3-ol-pyrogallol[4]arene $\left(\mathrm{PgC}_{3} \mathrm{OH}\right)$ has been cocrystallized with the fluorescent probe acenaphthlene in methanol. There exists a need to study cocrystallizations with more types of fluorescent probes with a variety of pyrogallol[4]arenes and solvents, not just $\mathrm{PgC}_{6}$

Department of Chemistry, University of Missouri, 601 South College Avenue, Columbia, Missouri 65211, USA. E-mail: AtwoodJ@missouri.edu

$\dagger$ CCDC 1012600-1012607. For crystallographic data in CIF or other electronic format see DOI: $10.1039 / \mathrm{c} 5 \mathrm{ce} 00771 \mathrm{~b}$ and $\mathrm{PgC}_{3} \mathrm{OH}$ in methanol and acetonitrile. Cocrystals with fluorescent probes can lead to insight into the chemical environment inside and outside the bowl of the pyrogallol[4]arene, intermolecular and intramolecular interactions, and the formation of novel supramolecular architectures. ${ }^{7}$

Even though there have been studies with pyrogallol[4]arenes and fluorescent probes, information is lacking regarding the factors influencing chemical environment and interactions. ${ }^{8}$ It has been shown that structural properties can be "finetuned" by changing the shape, size, and chemical composition of the components. ${ }^{9}$ More extensive studies are needed in order to learn more about the influence of characteristics such as aliphatic tail length and solvent systems on structural properties. In this study we examine cocrystals of rhodamine $B$ and of pyronin $Y$ with pyrogallol[4]arenes of different aliphatic chain length and in various solvent.

Herein is described two cocrystal systems: one with pyronin $\mathrm{Y}$ and one with rhodamine $\mathrm{B}$ (see Fig. 1). Cocrystals of pyronin $\mathrm{Y}$ with $C$-methylpyrogallol[4]arene $\left(\mathrm{PgC}_{1}\right)$ in methanol (cocrystal 1) and with $C$-ethylpyrogallol[4]arene $\left(\mathrm{PgC}_{2}\right)$ in ethanol (cocrystal 2) are described and analyzed. Additionally, cocrystals of rhodamine B with $\mathrm{PgC}_{1}$ in methanol (cocrystal 3) and ethanol (cocrystal 4), with $\mathrm{PgC}_{2}$ in ethanol (cocrystal 5), and with $C$-propylpyrogallol[4]arene $\left(\mathrm{PgC}_{3}\right)$ in methanol (cocrystal 6), ethanol (cocrystal 7), and acetonitrile (cocrystal 8) are examined.

\section{Experimental}

Reagents and solvents were obtained commercially and used without additional purification. $\mathrm{PgC}_{1}, \mathrm{PgC}_{2}$, and $\mathrm{PgC}_{3}$ were 


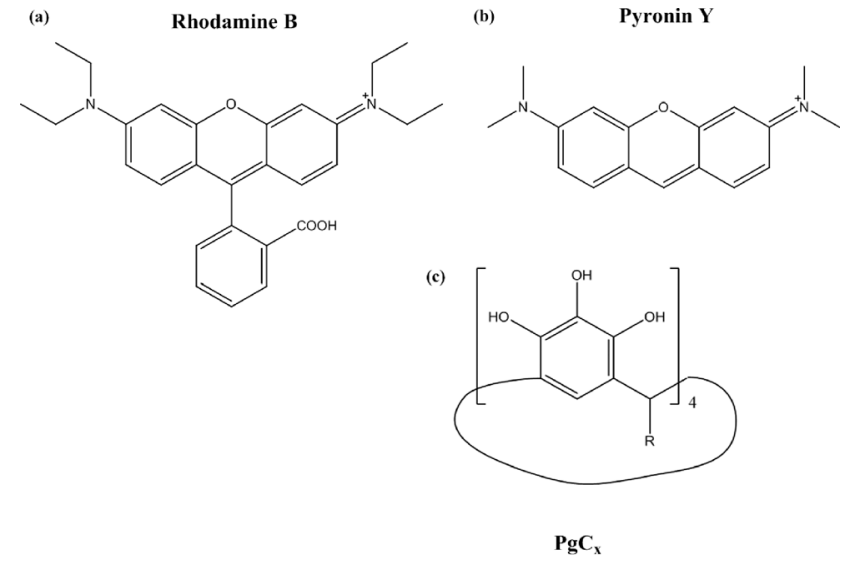

Fig. 1 Schematic structures of (a) rhodamine B, (b) pyronin $Y$, and (c) pyrogallol[4]arene.

synthesized using the previously reported method by Gerkensmeier et al., using acetaldehyde, propionaldehyde, and butyraldehyde as the respective aldehydes. ${ }^{10}$

Cocrystal 1 was crystallized by mixing $\mathrm{PgC}_{1}$ and pyronin $\mathrm{Y}$ in a 1:1 molar ratio $(0.1: 0.0497 \mathrm{~g})$ in $15 \mathrm{~mL}$ of methanol. The mixture was then sonicated for 30 minutes and allowed to slowly evaporate until crystallization of pink, prism-shaped crystals formed. In the same manner, cocrystal 2 was crystallized by mixing $\mathrm{PgC}_{2}$ and pyronin $\mathrm{Y}$ in a $1: 1$ molar ratio (0.05: $0.0228 \mathrm{~g}$ ) in $10 \mathrm{~mL}$ of ethanol and allowed to slowly evaporate until crystallization of pink, plate-shaped crystals.

Cocrystals 3-8 were all crystallized by dissolving $\operatorname{PgC}_{x}$ and rhodamine $\mathrm{B}$ in a 1:1 molar ratio $\left(0.1: 0.0788 \mathrm{~g}\right.$ for $\mathrm{PgC}_{1}$, 0.1:0.0721 $\mathrm{g}$ for $\mathrm{PgC}_{2}$, and 0.1:0.0665 $\mathrm{g}$ for $\mathrm{PgC}_{3}$ ) in a given amount of solvent (see Table 1). The mixture was then allowed to slowly evaporate. All crystallizations resulted in pink, prism- or plate-shaped crystals.

Single-crystal X-ray diffraction data for cocrystals $\mathbf{1}$ and $\mathbf{5}$ were collected with a Bruker Apex II CCD diffractometer at $173 \mathrm{~K}$ using $\mathrm{Cu} \mathrm{K} \alpha$ radiation $(\lambda=1.54178 \AA$ ). All single-crystal X-ray diffraction data for the other cocrystals was obtained with a Bruker Apex II CCD diffractometer at $173 \mathrm{~K}$ using Mo K $\alpha$ radiation $(\lambda=0.71073 \AA)$.

\section{Results}

All rhodamine B cocrystals are comprised of hydrogen bonded bilayer structures in which a rhodamine $\mathrm{B}$ molecule is endo to one $\mathrm{PgC}_{x}$ molecule: one part of the rhodamine $\mathrm{B}$ molecule is inside the bowl of the $\mathrm{PgC}_{x}$ molecule. Unless

Table 1 Type and amount of solvent used in cocrystallizations

\begin{tabular}{lll}
\hline Cocrystals & Solvent & Amount $(\mathrm{mL})$ \\
\hline 3 & Methanol & 15 \\
4 & Ethanol & 20 \\
5 & Ethanol & 10 \\
6 & Methanol & 20 \\
7 & Ethanol & 15 \\
8 & Acetonitrile & 15
\end{tabular}

otherwise noted, the $-\mathrm{N}\left(\mathrm{CH}_{2} \mathrm{CH}_{3}\right)_{2}$ group of the rhodamine $\mathrm{B}$ molecule is the endo part of the rhodamine $\mathrm{B}$ molecule in the bowl of the $\mathrm{PgC}_{x}$ molecule and is oriented vertically (see Fig. 2). One important characteristic examined in both types of cocrystals is the $\mathrm{C}-\mathrm{H} \cdots \pi$ distance. These comprise interactions involving a calculated centroid (the $\pi$-electron density) of an aromatic group donating to a hydrogen atom bonded to a carbon atom. A second important structural feature is the cross-sectional distance. This is the distance between opposite middle hydroxyl groups on the rim of the $\mathrm{PgC}_{x}$ molecule (see Fig. 3). When these distances differ by less than $0.75 \AA$, the bowl of the pyrogallol[4] arene is referred to as conical and when the distances differ by more than $0.75 \AA$ the bowl of the pyrogallol[4] arene is referred to as pinched. Additionally, when discussing the oxygen atoms of the rhodamine B molecule, the oxygen atom in the ring system is not involved in any hydrogen bonding unless otherwise noted.

\section{Cocrystal 1}

There are one pyronin $\mathrm{Y}$ molecule, one $\mathrm{PgC}_{1}$ molecule, five methanol molecules, and three water molecules in the asymmetric unit of cocrystal $\mathbf{1}$. Two of the water molecules are disordered; one is modeled at $50 \%$ occupancy and six are modeled at $25 \%$ occupancy. The $\mathrm{PgC}_{1}$ bowl is nearly conical; the cross-sectional distances are $8.24 \AA$ and $8.75 \AA$. The $-\mathrm{N}\left(\mathrm{CH}_{3}\right)_{2}$ group is endo to the bowl of the $\mathrm{PgC}_{1}$. Three probes are stacked directly on top of each other in the center of four $\mathrm{PgC}_{1}$ molecules (forming a square with the $\mathrm{PgC}_{1}$ molecules at the corners and the upper-rim hydroxyl groups pointing towards the center of the square) (see Fig. 4). The $\mathrm{PgC}_{1}$ molecules form a tube-like structure in which the pyronin $\mathrm{Y}$ molecules pack in the empty space of the tube (see Fig. 5). In total, the $\mathrm{PgC}_{1}$ molecule participates in twelve hydrogen bonds $\left(1.87-2.20 \AA(\mathrm{H} \cdots \mathrm{A}), 1^{109.8-168.1^{\circ}}(\mathrm{O}-\mathrm{H} \cdots \mathrm{A})\right)$. Three of the hydrogen bonds are intramolecular hydrogen bonds between the upper-rim hydroxyl groups and two of the hydrogen bonds are intermolecular hydrogen bonds to hydroxyl

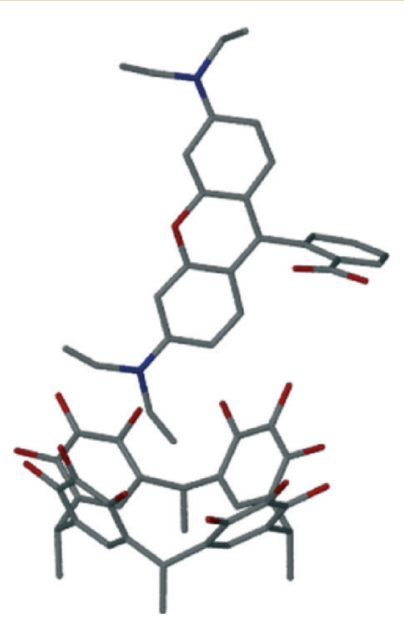

Fig. 2 Vertical arrangement of the rhodamine B guest. Solvent molecules and hydrogen atoms are omitted for clarity. 


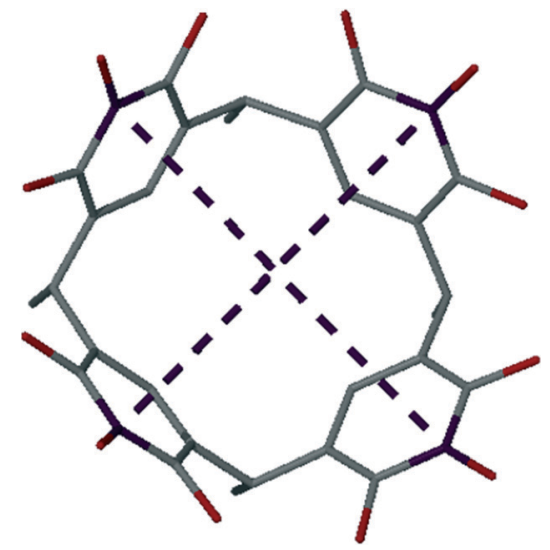

Fig. 3 Distances across the pyrogallol[4]arene bowl (cross-sectional distances).

(a)

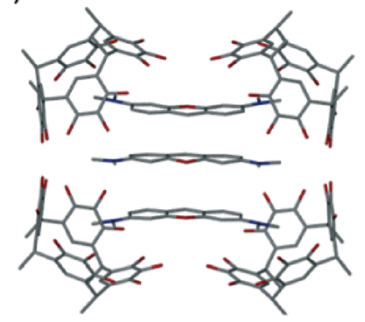

(b)

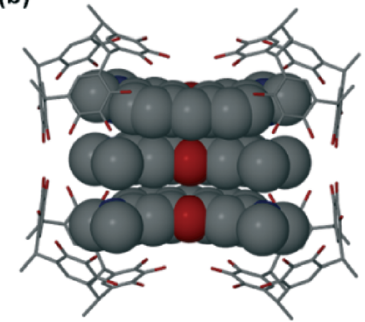

Fig. 4 Arrangement of $\mathrm{PgC}_{1}$ molecules with the guest molecule pyronin $Y$ in (a) stick representantion and (b) with space-filled pyronin $Y$ molecules. Solvent molecules and hydrogen atoms are omitted for clarity.

groups of an adjacent $\mathrm{PgC}_{1}$ molecules. The remaining seven hydroxyl groups are donating and accepting hydrogen bonds from methanol molecules which also act as a bridge between adjacent $\mathrm{PgC}_{1}$ molecules. In addition to the $\mathrm{O}-\mathrm{H} \cdots \mathrm{A}$ hydrogen bonding, there are $\mathrm{C}-\mathrm{H} \cdots \pi$ interactions. The $-\mathrm{N}\left(\mathrm{CH}_{3}\right)_{2}$ group which is endo to the bowl of the $\mathrm{PgC}_{1}$ molecule donates a hydrogen atom from each methyl group to two different aromatic centroids of the $\mathrm{PgC}_{1}$ molecule $(2.90 \AA$ $\left.(\mathrm{C}-\mathrm{H} \cdots \pi),{ }^{20.6^{\circ}}(\mathrm{C}-\mathrm{H} \cdots \pi) ; 3.03 \AA(\mathrm{C}-\mathrm{H} \cdots \pi), 130.8^{\circ}(\mathrm{C}-\mathrm{H} \cdots \pi)\right)$. Furthermore, an adjacent tail hydrogen of a $\mathrm{PgC}_{1}$ molecule, $\mathrm{C}-\mathrm{H} \cdots \pi$ interacts with the aromatic centroid $(2.84 \AA(\mathrm{C}-\mathrm{H} \cdots \pi)$, $\left.124.4^{\circ}\left(\mathrm{C}-\mathrm{H}^{\cdots} \cdots \pi\right)\right)$.

\section{Cocrystal 2}

Cocrystal 2 has an asymmetric unit which contains one endopyronin $\mathrm{Y}$ molecule, one $\mathrm{PgC}_{2}$ molecule, one ethanol molecule, and two chloride ions (see Fig. 6). The ethanol molecule is disordered over two positions and is modeled at $60 \%$ and $40 \%$. One of the chloride ions is disordered over two positions and is modeled at $50 \%$ and the second chloride ion is disordered over five positions and is modeled at $30 \%, 20 \%$, $20 \%, 15 \%$, and $15 \%$. The bowl of the pyrogallol[4] arene is pinched and has cross-sectional distances of $6.30 \AA$ and 9.83 A. Unlike cocrystal 1 , the $\mathrm{PgC}_{2}$ molecules pack in a

(a)
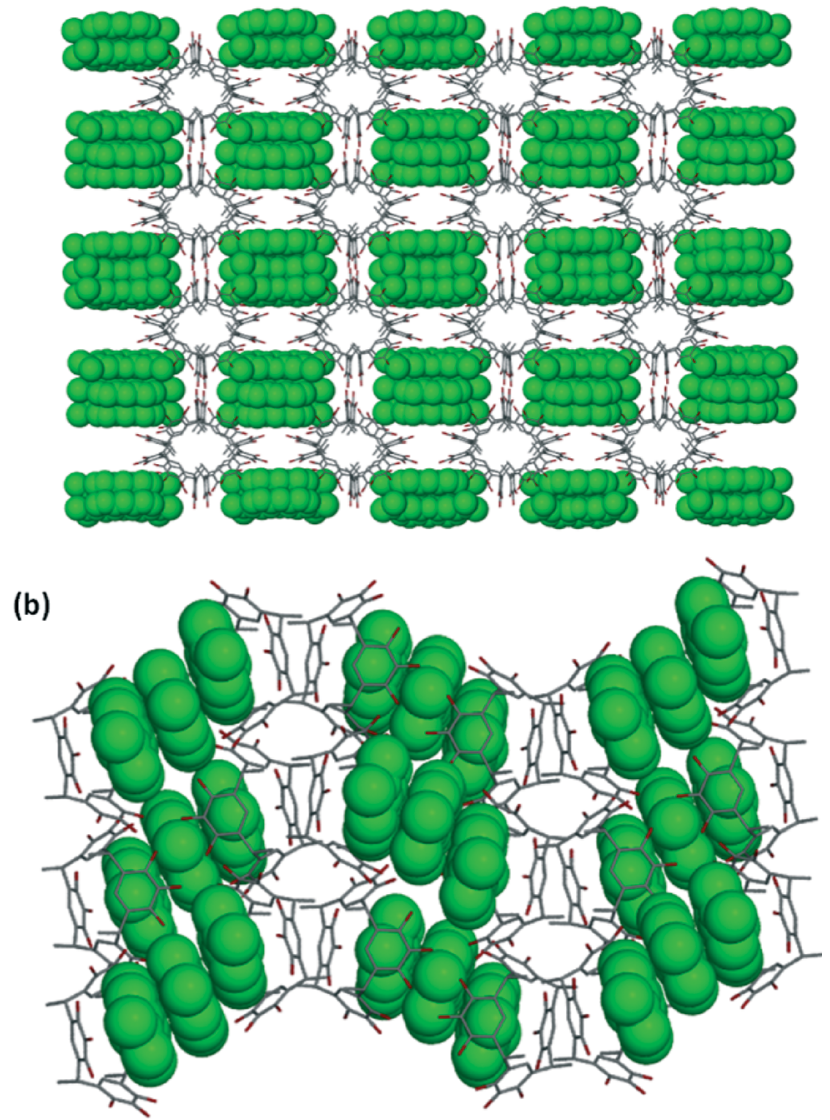

Fig. 5 Packing of the $\mathrm{PgC}_{1}$ molecules and pyronin $\mathrm{Y}$ molecules along the (a) $b$-axis and (b) the a-axis. The pyronin $Y$ molecules are in green and in space-filled representation. Solvent molecules and hydrogen atoms are removed for clarity.

typical bilayer arrangement and the endo pyronin Y molecule is arranged horizontally (aligned with the bowl). Throughout the crystal lattice, the hydroxyl groups of the $\mathrm{PgC}_{2}$ molecule participate in fifteen hydrogen bonds $(1.66-2.37 \AA(\mathrm{H} \cdots \mathrm{A})$, 109.1-162.2 ${ }^{\circ}(\mathrm{O}-\mathrm{H} \cdots \mathrm{A})$ ) (see Fig. 7). Five of the hydrogen

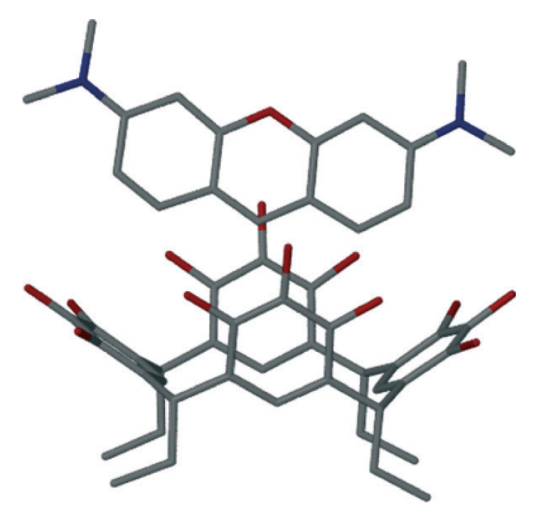

Fig. 6 The asymmetric unit of cocrystal 2, $\mathrm{C}_{36} \mathrm{H}_{40} \mathrm{O}_{12} \cdot \mathrm{C}_{17} \mathrm{H}_{19} \mathrm{ON}_{2}$ $\cdot \mathrm{C}_{2} \mathrm{H}_{5} \mathrm{OH} \cdot 2 \mathrm{Cl}^{-}$. The pyronin $\mathrm{Y}$ molecule is arranged horizontally. Ethanol molecules, chloride ions, and hydrogen atoms are removed for clarity. 

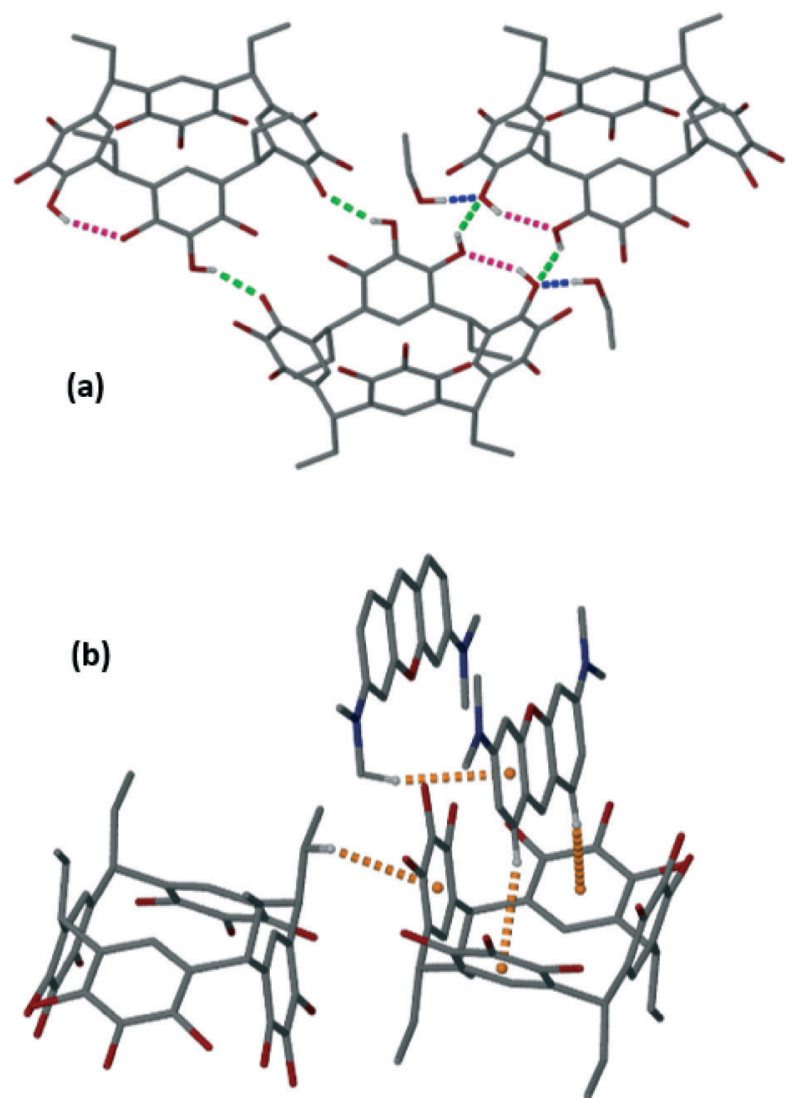

Fig. 7 Bonding present in cocrystal 2. (a) Hydrogen bonding: intermolecular hydrogen bonding in dashed green bonds, intramolecular hydrogen bonding in dashed pink bonds, solvent hydrogen bonding in blue dashed bonds. (b) $\mathrm{C}-\mathrm{H} \cdots \pi$ bonding (orange dashed bonds). All other solvent molecules and hydrogen atoms are omitted for clarity.

bonds are intramolecular hydrogen bonds among the hydroxyl groups of the $\mathrm{PgC}_{2}$ molecule, and five are intermolecular hydrogen bonds among hydroxyl groups of adjacent $\mathrm{PgC}_{2}$ molecules. Furthermore, there are three hydrogen bonds to the chloride ions and two hydrogen bonds with ethanol molecules. In addition to the $\mathrm{O}-\mathrm{H} \cdots \mathrm{A}$ hydrogen bonds, the $\mathrm{PgC}_{2}$ molecule is also participating in three $\mathrm{C}-\mathrm{H} \cdots \pi$ interactions: two from two hydrogen atoms on the endo pyronin $\mathrm{Y}$ molecule donating to the centroids of the $\mathrm{PgC}_{2}$ molecule and one from one hydrogen atom on a carbon tail group of an adjacent $\mathrm{PgC}_{2}$ molecule $\left(2.80-2.99 \AA(\mathrm{C}-\mathrm{H} \cdots \pi), 123.5-166.8^{\circ}\right.$ $(\mathrm{C}-\mathrm{H} \cdots \pi))$. The pyronin $\mathrm{Y}$ molecule is also involved in a $\mathrm{C}-\mathrm{H} \cdots \pi$ interaction. One hydrogen atom from the $-\mathrm{N}\left(\mathrm{CH}_{3}\right)_{2}$ group of a pyronin $\mathrm{Y}$ molecule donates to an aromatic ring containing a $-\mathrm{N}\left(\mathrm{CH}_{3}\right)_{2}$ group of a second pyronin $\mathrm{Y}$ molecule $\left(2.98 \AA(\mathrm{C}-\mathrm{H} \cdots \pi), 151.7^{\circ}(\mathrm{C}-\mathrm{H} \cdots \pi)\right)$.

\section{Cocrystal 3}

In the asymmetric unit there are one rhodamine molecule, one $\mathrm{PgC}_{1}$ molecule, and five methanol molecules (see Fig. 8). The cross-sectional distances are $7.87 \AA$ and $9.02 \AA$, meaning the bowl is pinched. Throughout the crystal lattice, there is
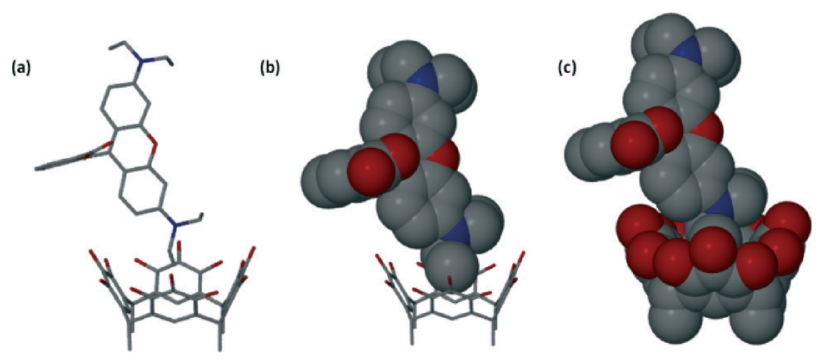

Fig. 8 Asymmetric unit of cocrystal $3, \mathrm{C}_{32} \mathrm{H}_{32} \mathrm{O}_{12} \cdot \mathrm{C}_{28} \mathrm{H}_{30} \mathrm{O}_{3} \mathrm{~N}_{2} \cdot 5 \mathrm{CH}_{3} \mathrm{OH}$, in (a) stick representation, (b) stick representation of the $\mathrm{PgC}_{1}$ molecule and space-filled representation of the rhodamine $B$ molecule, and (c) space-filled representation. All solvent and hydrogen atoms are omitted for clarity.

an extensive hydrogen bonding network. In total there are fifteen hydrogen bonds in which the hydroxyl groups of the $\mathrm{PgC}_{1}$ molecule participate (1.80-2.09 $\AA$ ( $\left.\mathrm{H} \cdots \mathrm{A}\right), 143.1-171.9^{\circ}$ $(\mathrm{O}-\mathrm{H} \cdots \mathrm{A}))$. Five of the hydrogen bonds are intramolecular hydrogen bonds between the upper-rim hydroxyl groups while four are intermolecular hydrogen bonds between hydroxyl groups of adjacent $\mathrm{PgC}_{1}$ molecules. Two of the hydrogen bonds are hydroxyl hydrogen atoms donating to the oxygen atoms of a rhodamine $\mathrm{B}$ molecule. The remaining five hydrogen bonds are between the hydroxyl groups and methanol molecules. The methanol molecules act as a bridge between the $\mathrm{PgC}_{1}$ molecules as a result of the hydrogen bond; four hydroxyl hydrogen atoms donate to the methanol oxygen atom and the methanol hydroxyl hydrogen atom then donates to an adjacent hydroxyl oxygen atom of a $\mathrm{PgC}_{1}$ molecule. Along with the hydrogen bonding already described for the rhodamine $\mathrm{B}$ molecule, there is also a hydrogen bond involving a methanol hydroxyl hydrogen atom and an oxygen atom of the rhodamine $\mathrm{B}$ molecule $\left(1.88 \AA(\mathrm{H} \cdots \mathrm{O}), 173.8^{\circ}\right.$ $(\mathrm{O}-\mathrm{H} \cdots \mathrm{O}))$. As well as $\mathrm{O}-\mathrm{H} \cdots \mathrm{A}$ hydrogen bonding, there are two $\mathrm{C}-\mathrm{H} \cdots \pi$ interactions present with the $\mathrm{PgC}_{1}$ molecule and the endo rhodamine $\mathrm{B}$ molecule $\left(2.79 \AA(\mathrm{C}-\mathrm{H} \cdots \pi), 1^{148.0^{\circ}}\right.$ $\left.(\mathrm{C}-\mathrm{H} \cdots \pi) ; 3.03 \AA(\mathrm{C}-\mathrm{H} \cdots \pi), 132.6^{\circ}(\mathrm{C}-\mathrm{H} \cdots \pi)\right)$.

\section{Cocrystal 4}

Within the asymmetric unit of cocrystal 4 there are one rhodamine $\mathrm{B}$ molecule, one $\mathrm{PgC}_{1}$ molecule, and three ethanol molecules. One of the ethanol molecules is disordered and is modelled at $72 \%$ and $28 \%$. The rhodamine B molecule resides within the cavity (endo) of the $\mathrm{PgC}_{1}$ molecule and the pyrogallol[4]arene molecules pack in a bilayer arrangement (see Fig. 9). With cross-sectional distances of $8.30 \AA$ and $8.73 \AA$, the $\mathrm{PgC}_{1}$ molecule takes on a more conical shape. There is a complex hydrogen bonding network throughout the cocrystal system. The $\mathrm{PgC}_{1}$ molecule is participating in fifteen hydrogen bonds (1.77-2.21 $\AA$ ( $\left.\mathrm{H}^{\cdots} \mathrm{A}\right), 114.6-178.4^{\circ}$ $(\mathrm{O}-\mathrm{H} \cdots \mathrm{A}))$. There are five intramolecular hydrogen bonds involving the hydroxyl groups around the upper-rim of each $\mathrm{PgC}_{1}$ molecule along with two intermolecular hydrogen bonds. Six hydrogen bonds involve the hydroxyl groups of the 
(a)

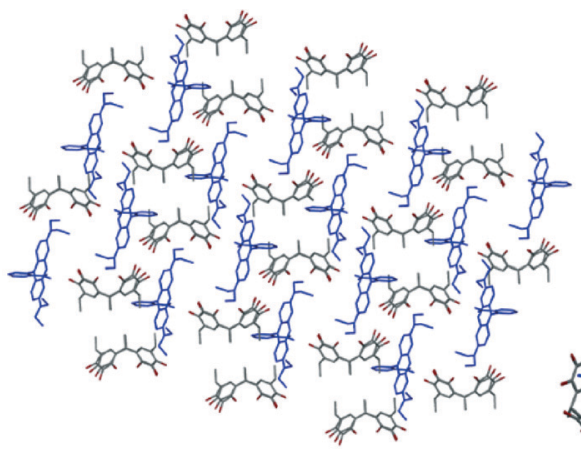

(b)

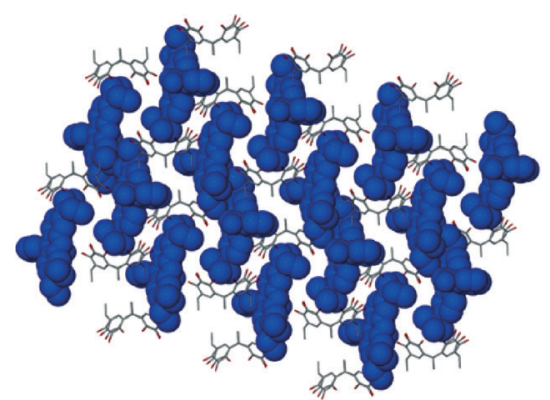

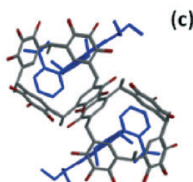

(c)

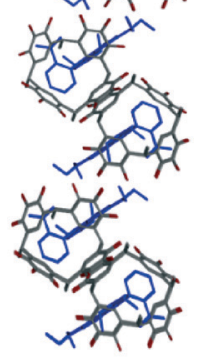

Fig. 9 Bilayer packing arrangement of cocrystal 4 in (a) stick representation, (b) space-filled rhodamine B molecules (in blue) and stick representation of the pyrogallol[4]arene molecules along the $b$-axis. (c) Bilayer packing along the a-axis. Solvent and hydrogen atoms are omitted for clarity.

$\mathrm{PgC}_{1}$ molecules and ethanol molecules. The ethanol molecules act as a bridge between $\mathrm{PgC}_{1}$ molecules. The remaining two hydrogen bonds are donated from the hydroxyl groups of the $\mathrm{PgC}_{1}$ molecule to the oxygen atoms of the rhodamine $\mathrm{B}$ molecule. In addition to $\mathrm{O}-\mathrm{H} \cdots \mathrm{A}$ bonding, $\mathrm{C}-\mathrm{H} \cdots \pi$ interactions are also present within the system. The aromatic rings of the $\mathrm{PgC}_{1}$ molecule $\mathrm{C}-\mathrm{H}^{\cdots} \cdots \pi$ interact with two hydrogen atoms of the $-\mathrm{N}\left(\mathrm{CH}_{2} \mathrm{CH}_{3}\right)$ group on the endo rhodamine $\mathrm{B}$ molecule $\left(2.75 \AA\left(\mathrm{C}-\mathrm{H}^{\cdots} \cdots \pi\right), 133.7^{\circ}\left(\mathrm{C}-\mathrm{H}^{\cdots} \cdots \pi\right)\right)$. There are also two $\mathrm{C}-\mathrm{H} \cdots \pi$ interactions to the aromatic rings of the $\mathrm{PgC}_{1}$ molecule from hydrogen atoms on a $-\mathrm{N}\left(\mathrm{CH}_{2} \mathrm{CH}_{3}\right)$ group of the exo rhodamine $\mathrm{B}$ molecule $\left(2.79 \AA\left(\mathrm{C}-\mathrm{H}^{\cdots} \pi\right), 123.3^{\circ}\right.$ $\left.(\mathrm{C}-\mathrm{H} \cdots \pi) ; 3.01 \AA(\mathrm{C}-\mathrm{H} \cdots \pi), 148.8^{\circ}\left(\mathrm{C}-\mathrm{H}^{\cdots} \cdots \pi\right)\right)$ and one from a hydrogen atom on the phenyl group containing the carbonyl groups $\left(2.93 \AA\left(\mathrm{C}-\mathrm{H}^{\cdots} \cdots \pi\right), 151.0^{\circ}\left(\mathrm{C}-\mathrm{H}^{\cdots} \pi\right)\right)$. One of the aromatic groups containing the $-\mathrm{N}\left(\mathrm{CH}_{2} \mathrm{CH}_{3}\right)$ group of the rhodamine $\mathrm{B}$ molecule has a $\mathrm{C}-\mathrm{H} \cdots \pi$ interaction with a hydrogen atom on one of the carbon tail groups of the $\mathrm{PgC}_{1}$ molecule $\left(2.89 \AA\left(\mathrm{C}-\mathrm{H}^{\cdots} \cdots \pi\right), 152.2^{\circ}\left(\mathrm{C}-\mathrm{H}^{\cdots} \cdots \pi\right)\right)$.

\section{Cocrystal 5}

There are one rhodamine $\mathrm{B}$ molecule, one $\mathrm{PgC}_{2}$ molecule, two ethanol molecules, and two water molecules in the asymmetric unit of cocrystal 5. Both of the ethanol molecules are disordered over two positions; the first modelled at $65 \%$ and $35 \%$ and the second modelled at $77 \%$ and $23 \%$. Crosssectional distances are $8.44 \AA$ and $8.65 \AA$. As with cocrystals 3 and 4 , there is extensive hydrogen bonding throughout the

cocrystal network. Overall, there are thirteen hydrogen bonds the $\mathrm{PgC}_{2}$ molecule is involved in $(1.76-2.19 \AA(\mathrm{H} \cdots \mathrm{A}), 122.4-$ $173.0^{\circ}(\mathrm{O}-\mathrm{H} \cdots \mathrm{A})$ ) (see Fig. 10). Four of these are intramolecular hydrogen bonds between hydroxyl groups and two are intermolecular hydrogen bonds between hydroxyl groups of adjacent $\mathrm{PgC}_{2}$ molecules. Additional hydrogen bonding occurs with hydrogen bonds donated from the hydrogen atoms of two hydroxyl groups to the oxygen atoms of an exo rhodamine B molecule. As in cocrystals 3 and 4 , the ethanol molecules act as a bridge between $\mathrm{PgC}_{2}$ molecules However, it takes two ethanol molecules to act as a bridge, not one solvent molecule as in cocrystals 3 and 4. Four hydroxyl hydrogen atoms donate hydrogen bonds to ethanol oxygen atoms whereas the hydroxyl hydrogen atom on that ethanol molecule then hydrogen bonds to the oxygen of an adjacent ethanol molecule $\left(1.84 \AA\left(\mathrm{O}-\mathrm{H}^{\cdots} \mathrm{O}\right), 150.8^{\circ}(\mathrm{O}-\mathrm{H} \cdots \mathrm{O})\right)$. Two of those hydroxyl hydrogen atoms of the ethanol molecules donate hydrogen bonds to $\mathrm{PgC}_{2}$ hydroxyl oxygen atoms. In conjunction with the $\mathrm{O}-\mathrm{H} \cdots \mathrm{A}$ hydrogen bonding, there are $\mathrm{C}-\mathrm{H} \cdots \pi$ interactions involving both the aromatic groups of the $\mathrm{PgC}_{2}$ molecule and the rhodamine $\mathrm{B}$ molecule. The endo rhodamine $\mathrm{B}$ molecule has $\mathrm{C}-\mathrm{H} \cdots \pi$ interactions with three aromatic groups of the $\mathrm{PgC}_{2}$ molecule $(2.68-3.00 \AA$ (C-H $\cdots \pi)$, $\left.109.9-141.9^{\circ}(\mathrm{C}-\mathrm{H} \cdots \pi)\right)$. The tail groups of the $\mathrm{PgC}_{2}$ molecules $\mathrm{C}-\mathrm{H} \cdots \pi$ interact with the aromatic groups of the rhodamine $\mathrm{B}$ molecule; one to one of the aromatic groups containing the $-\mathrm{N}\left(\mathrm{CH}_{2} \mathrm{CH}_{3}\right)_{2}$ group $\left(2.88 \AA(\mathrm{C}-\mathrm{H} \cdots \pi), 149.2^{\circ}\right.$ $(\mathrm{C}-\mathrm{H} \cdots \pi))$ and one to the aromatic group containing the carbonyl groups $\left(2.72 \AA\left(\mathrm{C}-\mathrm{H}^{\cdots} \cdots \pi\right), 157.6^{\circ}\left(\mathrm{C}-\mathrm{H}^{\cdots} \cdots\right)\right)$.

\section{Cocrystal 6}

The asymmetric unit of cocrystal 6 contains one rhodamine B molecule, one $\mathrm{PgC}_{3}$ molecule, and five methanol molecules. Two of the tail groups of the $\mathrm{PgC}_{3}$ molecule are disordered. One of the tail groups is disordered over two positions and is

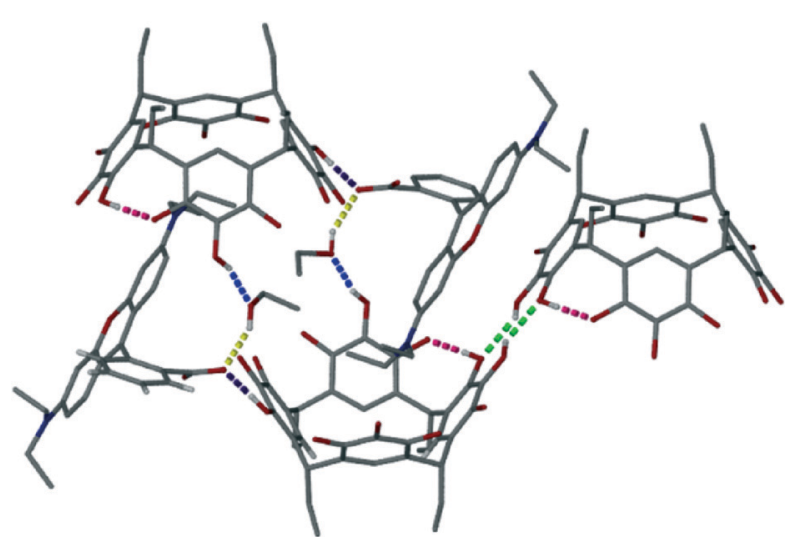

Fig. 10 Types of hydrogen bonds found in cocrystal 5. Intermolecular hydrogen bonds are green dashed bonds, intramolecular hydrogen bonds are pink dashed bonds, solvent hydrogen bonds with the $\mathrm{PgC}_{2}$ molecule are blue dashed lines, and solvent hydrogen bonds to rhodamine B molecules are yellow dashed lines. Other solvent molecules and hydrogen bonds are removed for clarity. 
modelled with parts at $40 \%$ and $60 \%$. The second tail group is also disordered over two positions and has parts modelled at $30 \%$ and $70 \%$. The cross-sectional distances are $8.25 \AA$ and 8.85 A. Once again, there is an extensive hydrogen bonding network. The $\mathrm{PgC}_{3}$ molecule is involved in seventeen different hydrogen bonds (1.84-2.21 $\AA$ ( $\left.\mathrm{H}^{\cdots} \mathrm{A}\right), 113.4-177.2^{\circ}$ $(\mathrm{O}-\mathrm{H} \cdots \mathrm{A}))$. Four of these bonds involve the intramolecular hydrogen bonding along the upper-rim hydroxyl groups of the $\mathrm{PgC}_{3}$ molecule. Additionally, there are four intermolecular hydrogen bonds between hydroxyl groups of adjacent pyrogallol[4]arenes. Two hydroxyl groups donate hydrogen bonds to the oxygen atoms on the rhodamine $\mathrm{B}$ molecule. The methanol molecules act as bridges, joining the $\mathrm{PgC}_{3}$ molecules together through four hydrogen bonds donated from hydroxyl groups to methanol molecules and three hydrogen bonds donated from the methanol molecules to the hydroxyl groups. The methanol molecules also act as a bridge between the rhodamine $\mathrm{B}$ molecule and $\mathrm{PgC}_{3}$ molecule with the methanol molecule donating a hydrogen bond to the rhodamine $\mathrm{B}$ oxygen atom and then a hydroxyl group donating a hydrogen bond to the methanol molecule $(2.11 \AA$ $\left.(\mathrm{H} \cdots \mathrm{O}), 132.9^{\circ}(\mathrm{O}-\mathrm{H} \cdots \mathrm{O})\right)$. Additional hydrogen bonding is occurring through four $\mathrm{C}-\mathrm{H} \cdots \pi$ interactions (see Fig. 11). There are two $\mathrm{C}-\mathrm{H} \cdots \pi$ interactions from aromatic rings of a $\mathrm{PgC}_{3}$ molecule to hydrogen on the endo $-\mathrm{N}\left(\mathrm{CH}_{2} \mathrm{CH}_{3}\right)$ group $\left(2.68 \AA(\mathrm{C}-\mathrm{H} \cdots \pi), 142.9^{\circ}(\mathrm{C}-\mathrm{H} \cdots \pi) ; 2.97 \AA(\mathrm{C}-\mathrm{H} \cdots \pi), 122.7^{\circ}\right.$ $(\mathrm{C}-\mathrm{H} \cdots \pi)$ ), and one $\mathrm{C}-\mathrm{H} \cdots \pi$ interaction from a $\mathrm{PgC}_{3}$ aromatic ring to an rhodamine $\mathrm{B}$ hydrogen atom on the phenyl group with the carbonyl oxygen atoms. The fourth $\mathrm{C}-\mathrm{H} \cdots \pi$

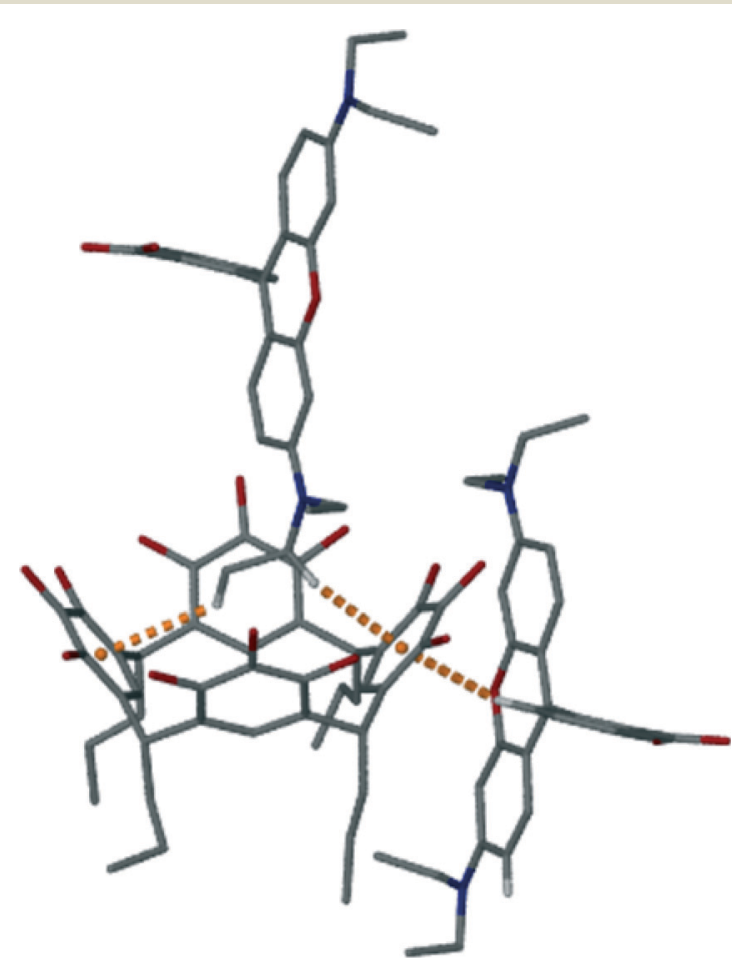

Fig. 11 The $\mathrm{C}-\mathrm{H} \cdots \pi$ interactions (orange dashed bonds) present in cocrystal 6. All solvent molecules and hydrogen atoms are omitted for clarity. interaction is the only $\mathrm{C}-\mathrm{H} \cdots \pi$ interaction from the aromatic groups of the rhodamine $\mathrm{B}$ molecule and it is to a solvent methanol molecule $\left(2.97 \AA\left(\mathrm{C}-\mathrm{H}^{\cdots} \cdots \pi\right), 143.3^{\circ}(\mathrm{C}-\mathrm{H} \cdots \pi)\right)$.

\section{Cocrystal 7}

Contained in the asymmetric unit of cocrystal 7 are one rhodamine $\mathrm{B}$ molecule, one $\mathrm{PgC}_{3}$ molecule, two ethanol molecules, and two water molecules. Both ethanol molecules are disordered; one of them is disordered over two positions and modeled at $57 \%$ and $43 \%$, and the second is disordered over an inversion center and modeled at $25 \%$. The cross-sectional distances are $7.48 \AA$ and $9.44 \AA$. The hydrogen bonding network of cocrystal 7 is similar to the hydrogen bonding network exhibited in the previously mentioned cocrystals. Overall, there are fifteen hydrogen bonds the $\mathrm{PgC}_{3}$ hydroxyl groups are participating in (1.80-2.11 $\AA$ ( $\mathrm{H} \cdots \mathrm{A}), 139.6-174.9^{\circ}$ $(\mathrm{O}-\mathrm{H} \cdots \mathrm{A}))$. Of these fifteen hydrogen bonds, four are intramolecular hydrogen bonds and four are intermolecular hydrogen bonds among hydroxyl groups of adjacent $\mathrm{PgC}_{3}$ molecules. Another two hydrogen bonds are from hydroxyl hydrogen atoms donating to water molecules. Again, the ethanol molecule acts as a bridge between $\mathrm{PgC}_{3}$ molecules with one hydroxyl hydrogen atom donating to an ethanol oxygen atom. Two ethanol hydroxyl hydrogens donate to two $\mathrm{PgC}_{3}$ hydroxyl groups. The remaining two hydrogen bonds arise from two hydroxyl hydrogen atoms donating to one oxygen atom on the rhodamine $\mathrm{B}$. Unlike the previous cocrystals, the rhodamine $\mathrm{B}$ does not hydrogen bond to any solvent molecules. Additional hydrogen bonding occurs through $\mathrm{C}-\mathrm{H} \cdots \pi$ interactions between the $\mathrm{PgC}_{3}$ and rhodamine $\mathrm{B}$ molecules. There is one $\mathrm{C}-\mathrm{H} \cdots \pi$ interaction from a $\mathrm{PgC}_{3}$ hydroxyl hydrogen atom to a rhodamine $\mathrm{B}$ aromatic group containing the oxygen atom $\left(2.90 \AA(\mathrm{C}-\mathrm{H} \cdots \pi), 98.7^{\circ}(\mathrm{C}-\mathrm{H} \cdots \pi)\right)$. The remaining $\mathrm{C}-\mathrm{H} \cdots \pi$ interactions involve the aromatic groups of the $\mathrm{PgC}_{3}$ molecule. Two of the aromatic groups $\mathrm{C}-\mathrm{H} \cdots \pi$ interact with hydrogen atoms of an endo rhodamine molecule on a $-\mathrm{N}\left(\mathrm{CH}_{2} \mathrm{CH}_{3}\right)_{2}$ group $\left(2.81 \AA(\mathrm{C}-\mathrm{H} \cdots \pi), 124.8^{\circ}(\mathrm{C}-\mathrm{H} \cdots \pi) ; 2.82 \AA\right.$ $\left.(\mathrm{C}-\mathrm{H} \cdots \pi),{ }^{132.1^{\circ}}(\mathrm{C}-\mathrm{H} \cdots \pi)\right)$. There are also two $\mathrm{C}-\mathrm{H} \cdots \pi$ interactions to two symmetry-generated, rhodamine $\mathrm{B}$ molecules: one to a hydrogen atom on a $-\mathrm{N}\left(\mathrm{CH}_{2} \mathrm{CH}_{3}\right)$ group (2.99 $\AA$ $\left.(\mathrm{C}-\mathrm{H} \cdots \pi), 132.6^{\circ}(\mathrm{C}-\mathrm{H} \cdots \pi)\right)$ and one to a hydrogen atom on the phenyl group containing the carbonyl groups $(2.71 \AA$ $\left.(\mathrm{C}-\mathrm{H} \cdots \pi), 157.8^{\circ}(\mathrm{C}-\mathrm{H} \cdots \pi)\right)$.

\section{Cocrystal 8}

In the asymmetric unit of cocrystal 8 there is one rhodamine $\mathrm{B}$ molecule, one $\mathrm{PgC}_{3}$ molecule, two and one half water molecules, and half of an acetonitrile. One of the water molecules is disordered over two positions and is modelled at $90 \%$ and $10 \%$. The acetonitrile molecule is disordered with two water molecules and the three molecules are modelled at $50 \%$, $25 \%$, and $25 \%$, respectively. One of the aliphatic tail groups on the $\mathrm{PgC}_{3}$ molecule is disordered over two positions and is modelled at $65 \%$ and $35 \%$. The macrocycle is in a pinched conformation; with cross-sectional distances $7.77 \AA$ and $9.09 \AA$ A. 
There is significantly less hydrogen bonding in cocrystal 8 than in the previous five cocrystals. There are only nine hydrogen bonds throughout the system (1.87-2.21 $\left.(\mathrm{O}-\mathrm{H} \cdots \mathrm{A}),{ }^{116.1-177.1^{\circ}}(\mathrm{O}-\mathrm{H} \cdots \mathrm{A})\right)$. In total there are three intramolecular bonds between the hydroxyl groups, two intermolecular bonds where the hydroxyl hydrogens donate to two adjacent $\mathrm{PgC}_{3}$ hydroxyl groups, three hydrogen bonds in which the hydroxyl hydrogens donate to three water molecules, and one hydrogen bond where a hydroxyl hydrogen atom donates to one of the oxygen atoms on the $-\mathrm{COOH}$ group of the rhodamine B molecule. Similar to cocrystal 7, the rhodamine $\mathrm{B}$ does not hydrogen bond to any solvent. Only the $\mathrm{PgC}_{3}$ molecule has $\mathrm{C}-\mathrm{H} \cdots \pi$ interactions. The $\mathrm{PgC}_{3}$ aromatic groups have $\mathrm{C}-\mathrm{H} \cdots \pi$ interactions with two of hydrogen atoms of the $-\mathrm{N}\left(\mathrm{CH}_{2} \mathrm{CH}_{3}\right)_{2}$ group on the endo rhodamine $\mathrm{B}$ molecule $\left(2.70 \AA(\mathrm{C}-\mathrm{H} \cdots \pi), 133.4^{\circ}(\mathrm{C}-\mathrm{H} \cdots \pi) ; 2.95 \AA\right.$ $\left.(\mathrm{C}-\mathrm{H} \cdots \pi), 119.3^{\circ}(\mathrm{C}-\mathrm{H} \cdots \pi)\right)$, one hydrogen atom on the $-\mathrm{N}\left(\mathrm{CH}_{2} \mathrm{CH}_{3}\right)_{2}$ group on a symmetry-generated rhodamine $\mathrm{B}$ molecule $\left(2.91 \AA(\mathrm{C}-\mathrm{H} \cdots \pi), 135.4^{\circ}(\mathrm{C}-\mathrm{H} \cdots \pi)\right)$, and one hydrogen atom of a $-\mathrm{COOH}$ containing phenyl group on a symmetry-generated rhodamine B molecule $(2.86 \AA(\mathrm{C}-\mathrm{H} \cdots \pi)$, $\left.169.2^{\circ}(\mathrm{C}-\mathrm{H} \cdots \pi)\right)$.

\section{Discussion}

There are many similarities between the rhodamine B containing cocrystals. All the cocrystals have similar hydrogen bonding schemes, a 1:1 ratio of probe to pyrogallol[4]arene, a bilayer packing arrangement, and a rhodamine $\mathrm{B}$ endo to the pyrogallol[4]arene molecule. However, changes in solvent and aliphatic tail length leads to differences in $\mathrm{C}-\mathrm{H} \cdots \pi$ interactions and hydrogen bonding.

Aliphatic tail length of the pyrogallol[4]arene molecules does seem to play a part in the $\mathrm{C}-\mathrm{H} \cdots \pi$ interactions and hydrogen bonding scheme of the cocrystals of rhodamine $\mathrm{B}$. In regards to the $\mathrm{C}-\mathrm{H} \cdots \pi$ interactions, with an aliphatic tail length of one carbon atom (cocrystals 3 and 6) the amount of $\mathrm{C}-\mathrm{H} \cdots \pi$ interactions to endo and symmetry-generated rhodamine B molecules remains consistent with two $\mathrm{C}-\mathrm{H} \cdots \pi$ interactions to an endo rhodamine $\mathrm{B}$. When aliphatic tail length is increased to two carbon atoms (cocrystals 4 and 7) the number of $\mathrm{C}-\mathrm{H} \cdots \pi$ interactions to symmetry-generated rhodamine B molecules increases from zero or one $\mathrm{C}-\mathrm{H} \cdots \pi$ interaction in cocrystals 6 and 3, respectively, (methanol cocrystals) to two $\mathrm{C}-\mathrm{H} \cdots \pi$ interactions (cocrystal 7) and three $\mathrm{C}-\mathrm{H} \cdots \pi$ interactions (cocrystals 4 ).

Changing the solvent has a small effect on the $\mathrm{C}-\mathrm{H} \cdots \pi$ interactions. When examining the $\mathrm{PgC}_{1}$ cocrystals (cocrystals 3 and 4), when the solvent is changed from methanol to ethanol, the number of $\mathrm{C}-\mathrm{H} \cdots \pi$ interactions between the $\mathrm{PgC}_{1}$ aromatic groups and the endo rhodamine $\mathrm{B}$ remain constant at two $\mathrm{C}-\mathrm{H} \cdots \pi$ interactions, but the number of $\mathrm{C}-\mathrm{H} \cdots \pi$ interactions involving the aromatic groups of the rhodamine $\mathrm{B}$ molecules and the interactions between the aromatic groups of the $\mathrm{PgC}_{1}$ molecules and exo, symmetry-generated rhodamine $\mathrm{B}$ molecules are greater in the ethanol cocrystals.
However, when examining the cocrystals containing $\mathrm{PgC}_{3}$ molecules (cocrystals 6, 7, and 8), the $\mathrm{C}-\mathrm{H} \cdots \pi$ interactions remain constant.

Aliphatic tail length along with the solvent, influences the resulting hydrogen bonding network in the rhodamine $\mathrm{B}$ cocrystals (see Table 2). With acetonitrile/water (cocrystal 8) there are significantly less hydrogen bonds than with the other cocrystals. Cocrystal 8 has only nine hydrogen bonds whereas the others have at least thirteen hydrogen bonds. It has fewer intramolecular hydrogen bonds and hydrogen bonds to rhodamine B. Methanol as a solvent (cocrystals 3 and 6) maintains a constant hydrogen bonding scheme with different aliphatic tail lengths. Both cocrystals have the same number of intramolecular hydrogen bonds, intermolecular hydrogen bonds, and hydrogen bonds to rhodamine B. With ethanol (cocrystals 4, 5, and 7), the hydrogen bonding does not remain constant with changing aliphatic tail lengths. Cocrystals 4 and 5 (aliphatic tail lengths of one and two carbon atoms, respectively) have double the number of intramolecular hydrogen bonds than intermolecular hydrogen bonds. However, when the aliphatic tail length is increased to three carbon atoms (cocrystal 7), then there is the same number of intramolecular and intermolecular hydrogen bonds. Finally, the number of solvent hydrogen bonds decreases as the aliphatic tail length increases. This is likely due to the fact there is water in cocrystals 5 and 7 so hydrogen bonding has to be shared between the main solvent and the water molecules.

In terms of solvent change, in cocrystals containing $\mathrm{PgC}_{1}$ molecules (cocrystals 3 and 4 ), the hydrogen bonding scheme remains consistent between the two cocrystals when the solvent changes from methanol to ethanol. However, in the cocrystals containing $\mathrm{PgC}_{3}$ molecules (cocrystals 6, 7, and 8) the hydrogen bonding scheme changes in regards to total number of hydrogen bonds, hydrogen bonds to water molecules, and hydrogen bonding to solvent molecules. When the solvent changes from methanol (cocrystal 6) to ethanol (cocrystal 7) to acetonitrile (cocrystals 8), the number of hydrogen bonds to solvent molecules decreases from seven hydrogen bonds to three hydrogen bonds to zero hydrogen bonds. Furthermore, when the solvent changes from methanol to ethanol to acetonitrile, the total number of hydrogen bonds also decreases from seventeen hydrogen bonds to fifteen hydrogen bonds to nine hydrogen bonds. When the solvent changes from methanol to ethanol to acetonitrile the

Table 2 Types and number of hydrogen bonds in the rhodamine B cocrystals

\begin{tabular}{lllllll}
\hline & $\begin{array}{l}\text { Intra } \\
\text { molecular }\end{array}$ & $\begin{array}{l}\text { Inter } \\
\text { molecular }\end{array}$ & Solvent & Water & B & Total \\
\hline 3 & 4 & 4 & 5 & 0 & 2 & 15 \\
$\mathbf{4}$ & 5 & 2 & 6 & 0 & 2 & 15 \\
5 & 4 & 2 & 3 & 2 & 2 & 13 \\
6 & 4 & 4 & 7 & 0 & 2 & 17 \\
7 & 4 & 4 & 3 & 2 & 2 & 15 \\
8 & 3 & 2 & 0 & 3 & 1 & 9
\end{tabular}


number of hydrogen bonds to water molecules increases from zero hydrogen bonds to two hydrogen bonds to three hydrogen bonds.

The only property that does not remain equivalent among the rhodamine B cocrystals is the shape of the pyrogallol[4]arene bowl. Cocrystals 4, 5, and 6 all have nearly conical bowls whereas cocrystals 3 and 7 have noticeably pinched cones (see Table 3). Cocrystals 3 and 7 are in different solvents and have different aliphatic tail lengths; thus there is no correlation between solvent, tail length, and bowl shape as of yet. One trend that seems to emerge is that rhodamine B prefers to be endo rather than exo to the pyrogallol[4]arene bowl.

Between the two pyronin Y structures, there are considerable differences between the supramolecular architecture, hydrogen bonding schemes, probe complexation, and bowl shape. Most notably, the supramolecular structure formed with $\mathrm{PgC}_{1}$ molecules (cocrystal 1) is a tube-like structure whereas $\mathrm{PgC}_{2}$ molecules (cocrystal 2) form a bilayer-type structure. Cocrystal 1 has more symmetry than cocrystal 2 resulting in different crystal unit parameters (see Table 4). Different packing motifs led to dissimilar hydrogen bonding schemes. With cocrystal $\mathbf{1}\left(\mathrm{PgC}_{1}\right)$, there are a total of twelve hydrogen bonds, while with cocrystal $2\left(\mathrm{PgC}_{2}\right)$ there are a total of fifteen hydrogen bonds. Cocrystal 1 also has more hydrogen bonds with solvent molecules (seven hydrogen bonds) than intermolecular and intramolecular hydrogen bonds (two and three hydrogen bonds, respectively). Cocrystal 2 has more intermolecular and intramolecular hydrogen bonds (five hydrogen bonds each) than solvent hydrogen bonds (two hydrogen bonds).

Along with the different packing arrangements and hydrogen bonding schemes of the $\mathrm{PgC}_{x}$ molecules, the probes have different orientations within the structure based on cocrystallization with $\mathrm{PgC}_{1}$ or $\mathrm{PgC}_{2}$ molecules. When cocrystallized with $\mathrm{PgC}_{1}$ molecules, the pyronin $\mathrm{Y}$ molecule is oriented vertically in the bowl of the $\mathrm{PgC}_{1}$ molecule. However, in cocrystal $2\left(\mathrm{PgC}_{2}\right)$ the pyronin $\mathrm{Y}$ molecule is oriented horizontally. Lastly, the bowl shape in the two cocrystals is dissimilar; cocrystal $1\left(\mathrm{PgC}_{1}\right)$ has a conical bowl $(8.24,8.75 \AA)$ and cocrystal $2\left(\mathrm{PgC}_{2}\right)$ has a pinched bowl (6.30, $9.83 \AA$ A $)$.

Although the two pyronin $\mathrm{Y}$ structures have different supramolecular architectures, hydrogen bonding schemes, probe orientation, and bowl shape they differ from their rhodamine B analogues in similar ways. First, both differ in their

Table 3 Comparison of the cross-sectional distances of cocrystals of rhodamine $B$

\begin{tabular}{llll}
\hline Cocrystal & $\begin{array}{l}\text { First } \\
\text { cross-sectional } \\
\text { distance }(\AA)\end{array}$ & $\begin{array}{l}\text { Second } \\
\text { cross-sectional } \\
\text { distance }(\AA)\end{array}$ & $\begin{array}{l}\text { Difference between } \\
\text { cross-sectional } \\
\text { distances }(\AA)\end{array}$ \\
\hline 3 & 7.87 & 9.02 & 1.15 \\
4 & 8.30 & 8.73 & 0.43 \\
5 & 8.44 & 8.65 & 0.21 \\
6 & 8.25 & 8.85 & 0.60 \\
7 & 7.48 & 9.44 & 1.96 \\
8 & 7.77 & 9.09 & 1.32
\end{tabular}

Table 4 Comparison of the cocrystals of pyronin $Y$

\begin{tabular}{lll}
\hline & Cocrystal 1 & Cocrystal 2 \\
\hline Pyrogallol[4]arene & PgC $_{1}$ & PgC $_{2}$ \\
Solvent & Methanol & Ethanol \\
Cell dimensions $\left(\AA,{ }^{\circ}\right)$ & $a=40.0943(8)$ & $a=14.103(2)$ \\
& $b=17.9485(4)$ & $b=14.457(2)$ \\
& $c=31.3076(8)$ & $c=15.357(3)$ \\
& $\alpha=90$ & $\alpha=63.031(2)$ \\
& $\beta=90$ & $\beta=69.038(2)$ \\
Volume $\left(\AA^{3}\right)$ & $\gamma=90$ & $\gamma=84.764(2)$ \\
Space group & $22530.0(9)$ & $2596.4(7)$ \\
Total hydrogen bonds & $C$ mca & $P \overline{1}$ \\
Solvent hydrogen bonds & 12 & 15 \\
Intramolecular hydrogen bonds & 7 & 2 \\
Intermolecular hydrogen bonds & 2 & 5 \\
Probe orientation & 2 & 5 \\
Bowl-shape & Vertical & Horizontal \\
& Conical & Pinched
\end{tabular}

bowl shapes. In cocrystal 1 ( $\mathrm{PgC}_{1}$, methanol, and pyronin $\left.\mathrm{Y}\right)$, the bowl of the $\mathrm{PgC}_{1}$ molecules is conical but in cocrystal 3 $\left(\mathrm{PgC}_{1}\right.$, methanol, and rhodamine $\left.\mathrm{B}\right)$ the bowl of the $\mathrm{PgC}_{1}$ is pinched. Both $\mathrm{PgC}_{2}$ analogues (cocrystal 2 (pyronin $\mathrm{Y}$ ) and 5 (rhodamine B)) also differ in bowl shape; cocrystal 2 has a pinched bowl but cocrystal 5 has a conical bowl. In regards to $\mathrm{C}-\mathrm{H} \cdots \pi$ interactions (see Table 5), cocrystals 1 and 2 (pyronin $\mathrm{Y}$ ) have one $\mathrm{C}-\mathrm{H} \cdots \pi$ interaction to an adjacent pyrogallol[4]arene molecule whereas cocrystals 3 and 5 (rhodamine B) do not have any $\mathrm{C}-\mathrm{H} \cdots \pi$ interactions to adjacent pyrogallol[4]arene molecules. Additionally when examining just the $\mathrm{PgC}_{2}$ cocrystals, compared to cocrystal 5 (rhodamine B), the $\mathrm{PgC}_{2}$ cocrystal of pyronin $\mathrm{Y}$ (cocrystal 2) has fewer $\mathrm{C}-\mathrm{H} \cdots \pi$ interactions overall (four interactions for cocrystal 2 and five interactions for cocrystal 5), $\mathrm{C}-\mathrm{H} \cdots \pi$ interactions involving the aromatic groups of the probe molecules (one for cocrystal 2 and two for cocrystal 5), and $\mathrm{C}-\mathrm{H} \cdots \pi$ interactions involving the aromatic groups of the pyrogallol[4]arene molecules and the hydrogen atoms of the probe molecules (two for cocrystal 2 and three for cocrystal 5). The trend is opposite in regards to the number of overall $\mathrm{C}-\mathrm{H} \cdots \pi$ interactions in cocrystals contacting $\mathrm{PgC}_{1}$ molecules. The pyronin cocrystal (cocrystal 1) has more $\mathrm{C}-\mathrm{H} \cdots \pi$ interactions than the rhodamine B cocrystal (cocrystal 3 ). Unlike with $\mathrm{C}-\mathrm{H} \cdots \pi$ interaction, the hydrogen bonding schemes are similar in the analogues (see Table 6) except for hydrogen bonding to the probe molecules and intermolecular hydrogen bonding in analogues of $\mathrm{PgC}_{2}$. In both rhodamine $\mathrm{B}$ cocrystals (3 and 5 ),

Table 5 Comparison of $\mathrm{C}-\mathrm{H} \cdots \pi$ interactions in cocrystal analogues of rhodamine $\mathrm{B}$ and pyronin $\mathrm{Y}$

\begin{tabular}{|c|c|c|c|c|}
\hline \multirow[b]{2}{*}{ Cocrystal } & \multicolumn{2}{|c|}{ Pyronin $\mathrm{Y}$} & \multicolumn{2}{|c|}{ rhodamine B } \\
\hline & 1 & 2 & 3 & 5 \\
\hline $\operatorname{PgC}_{x}$ & $\mathrm{PgC}_{1}$ & $\mathrm{PgC}_{2}$ & $\mathrm{PgC}_{1}$ & $\mathrm{PgC}_{2}$ \\
\hline Adjacent $\mathrm{PgC}_{x}$ molecules & 1 & 1 & 0 & 0 \\
\hline Probe aromatic groups & 0 & 1 & 0 & 2 \\
\hline $\mathrm{PgC}_{x}$ aromatic groups to probe & 2 & 2 & 2 & 3 \\
\hline Total & 3 & 4 & 2 & 5 \\
\hline
\end{tabular}


Table 6 Comparison of the hydrogen bonding in cocrystal analogues of rhodamine $B$ and pyronin $Y$

\begin{tabular}{lllll}
\hline & \multicolumn{2}{c}{ Pyronin $\mathrm{Y}$} & & \multicolumn{2}{c}{ rhodamine $\mathrm{B}$} \\
\hline Cocrystal & $\mathbf{1}$ & 2 & 3 & 5 \\
PgC $_{x}$ & $\mathrm{PgC}_{1}$ & $\mathrm{PgC}_{2}$ & $\mathrm{PgC}_{1}$ & $\mathrm{PgC}_{2}$ \\
Intramolecular & 3 & 5 & 4 & 4 \\
Intermolecular & 2 & 5 & 4 & 5 \\
Solvent & 7 & 2 & 5 & 3 \\
Water & 0 & 0 & 0 & 2 \\
Probe & 0 & 0 & 2 & 2 \\
Total & 12 & 12 & 15 & 16 \\
\hline
\end{tabular}

there are two hydrogen bonds with two hydroxyl hydrogen atoms donating to two different oxygen atoms on the rhodamine $\mathrm{B}-\mathrm{COOH}$ group. In the pyronin $\mathrm{Y}$ analogues, there are no hydrogen bonds to the pyronin molecule. In the $\mathrm{PgC}_{1}$ cocrystals (cocrystals 1 and 3), there are double the number of intermolecular hydrogen bonds in the rhodamine B cocrystal (cocrystal 3) than in the pyronin $\mathrm{Y}$ cocrystal (cocrystal 1). Finally, the packing arrangement differs in the analogues of $\mathrm{PgC}_{1}$ and $\mathrm{PgC}_{2}$ cocrystals (see Fig. 12). In the $\mathrm{PgC}_{1}$ cocrystals (cocrystals 1 and $3 \ddagger$ ), the pyronin $\mathrm{Y}$ cocrystal has a tube-like architecture while the rhodamine B cocrystal has a bilayer structure. In both $\mathrm{PgC}_{2}$ cocrystals (cocrystals 2 and 5), there is a bilayer structure; however, in the pyronin $\mathrm{Y}$ cocrystal (cocrystal 2) the probe molecules are aligned directly next to each other, but in the rhodamine B cocrystal (cocrystal 5) each end is aligned with the end of a different rhodamine B molecule. Even though both pyronin Y and rhodamine $B$ have similar backbone structures, the addition of the carboxylic phenyl group of the rhodamine B changes the bowl shape, crystal packing, and hydrogen bonding schemes of the resulting cocrystals.

\section{Conclusion}

Cocrystals of rhodamine B with various aliphatic chain lengths and solvent systems produce cocrystals that pack in a bilayer arrangement with one rhodamine $\mathrm{B}$ endo to the pyrogallol[4]arene bowl. Solvent does have an effect on the hydrogen bonding scheme. On the other hand, the two pyronin Y cocrystals (two different aliphatic chains and solvent systems) have significantly different supramolecular architectures (tube-like for $\mathrm{PgC}_{1}$ cocrystal, bilayer for $\mathrm{PgC}_{2}$ cocrystal), bowl shapes (conical for $\mathrm{PgC}_{1}$ cocrystal, pinched for $\mathrm{PgC}_{2}$ cocrystal), probe orientation (vertical for $\mathrm{PgC}_{1}$ (a)

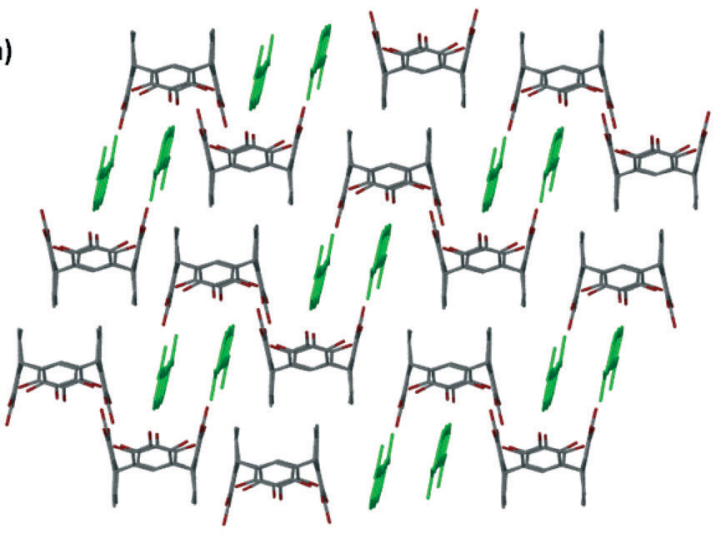

(c)

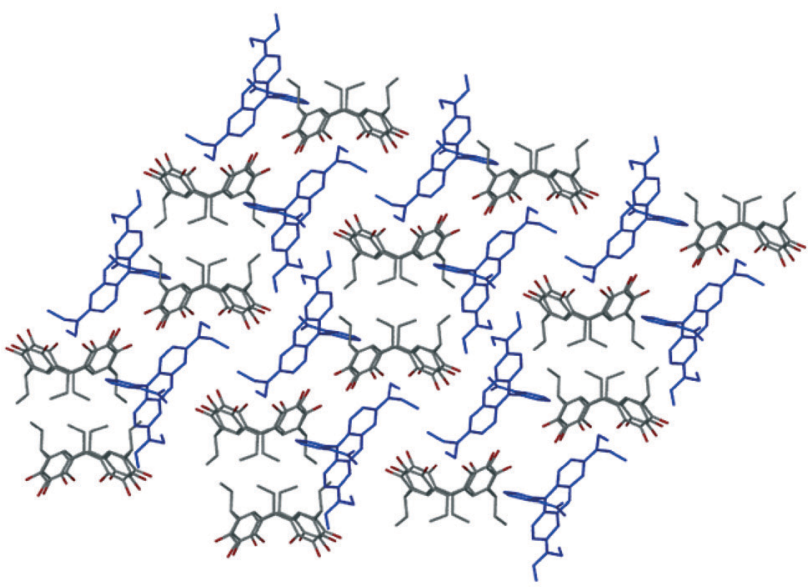

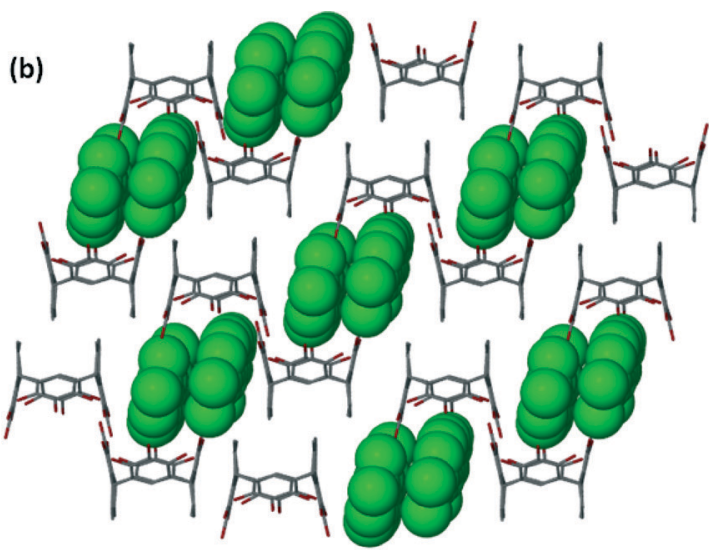

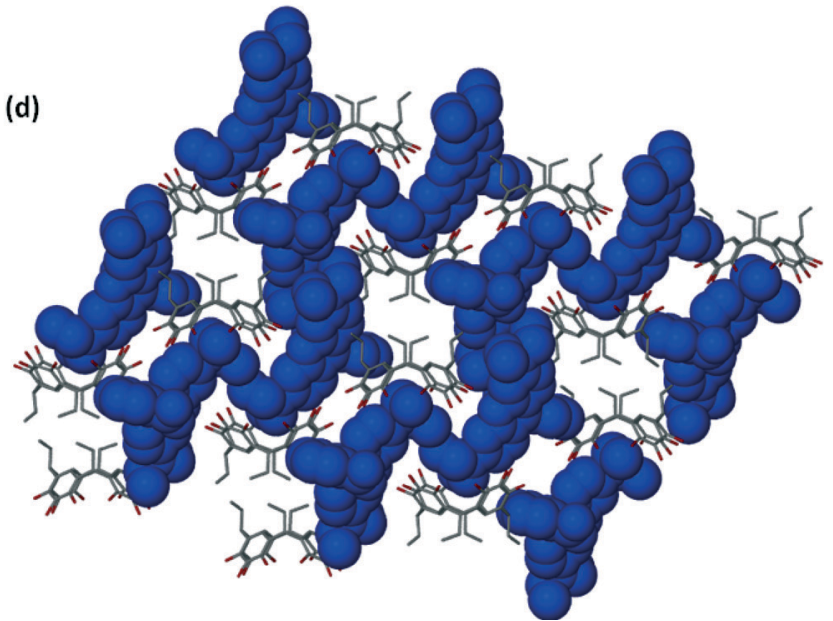

Fig. 12 Comparison of the packing arrangement of (a), (b) cocrystals $2\left(\mathrm{PgC}_{2}\right.$ and pyronin $\left.\mathrm{Y}\right)$ and (c), (d) cocrystal 5 ( $\mathrm{PgC} 2$ and rhodamine $\left.\mathrm{B}\right)$ in (a), (c) stick representation and (b), (d) space-filled guest molecules. Solvent molecules and hydrogen atoms are omitted for clarity. 
cocrystal, horizontal for $\mathrm{PgC}_{2}$ cocrystal), and hydrogen bonding schemes (more hydrogen bonds to solvent for $\mathrm{PgC}_{1}$ cocrystal, more intermolecular and intramolecular hydrogen bonds for $\mathrm{PgC}_{2}$ cocrystal). Thus, not only does solvent influence the final cocrystals but also the aliphatic chain length influences the final structure. The versatility of the cocrystals with solvents and pyrogallol[4]arene tail lengths, and the presence of multiple hydrogen bonding sites provides a good start to future insight into understanding the assembly of supramolecular architectures in the solid-state (i.e. intermolecular interactions) and the factors that affect particular types of assemblies.

\$ Crystallographic data - Cocrystal 1: $\mathrm{C}_{50.35} \mathrm{H}_{72.5} \mathrm{O}_{21.85} \mathrm{~N}_{1.5}, M=1048.40$, pink plate, $a=40.0943(8) \AA, b=17.9485(4) \AA, c=31.3076(8) \AA, \alpha=90^{\circ}, \beta=90^{\circ}, \gamma=$ $90^{\circ}$, space group Cmca, $V=22530(9) \AA^{3}, Z=16, D_{\mathrm{c}}=1.236 \mathrm{~g} \mathrm{~cm}^{-3}, F_{000}=8958$, $\mathrm{Cu} \mathrm{K} \alpha$ radiation, $\lambda=1.5178 \AA, T=173 \mathrm{~K}, 10285$ reflections collected. Final GooF $=2.039, R_{1}=0.124, \mathrm{w} R_{2}=0.430, R$ indices based on reflections with $I>2 \sigma(I)$ (refinement on $F^{2}$ ), 730 parameters, 5 restraints. Lp and absorption corrections applied, $\mu=0.815 \mathrm{~mm}^{-1}$. Cocrystal 2: $\mathrm{C}_{55} \mathrm{H}_{65} \mathrm{O}_{14} \mathrm{~N}_{2} \mathrm{Cl}_{2}, M=1048.99$, pink plate, $a$ $=14.103(2) \AA, b=14.457(2) \AA, c=15.357(3) \AA, \alpha=63.031(2)^{\circ}, \beta=69.038(2)^{\circ}, \gamma=$ 84.764(2) $)^{\circ}$, space group $P \overline{1}, V=2596.4(7) \AA^{3}, Z=2, D_{\mathrm{c}}=1.342 \mathrm{~g} \mathrm{~cm}^{-3}, F_{000}=1110$, Mo K $\alpha$ radiation, $\lambda=0.71073 \AA, T=173 \mathrm{~K}, 11415$ reflections collected. Final GooF $=1.036, R_{1}=0.092, \mathrm{w} R_{2}=0.219, R$ indices based on reflections with $I>2$ $\sigma(I)$ (refinement on $F^{2}$ ), 699 parameters, 156 restraints. Lp and absorption corrections applied, $\mu=0.194 \mathrm{~mm}^{-1}$. Cocrystal 3: $\mathrm{C}_{65} \mathrm{H}_{82} \mathrm{O}_{20} \mathrm{~N}_{2}, M=1211.33$, pink plate, $a=12.499(3) \AA, b=15.400(4) \AA, c=17.164(4) \AA, \alpha=79.589(3)^{\circ}, \beta=$ $74.873(3)^{\circ}, \gamma=81.892(3)^{\circ}$, space group $P \overline{1}, V=3121.4(14) \AA^{3}, Z=2, D_{\mathrm{c}}=1.289 \mathrm{~g}$ $\mathrm{cm}^{-3}, F_{000}=1292$, Mo K $\alpha$ radiation, $\lambda=0.71073 \AA, T=173 \mathrm{~K}, 12869$ reflections collected. Final GooF $=1.026, R 1=0.052, \mathrm{w} R_{2}=0.113, R$ indices based on reflections with $I>2 \sigma(I)$ (refinement on $F^{2}$ ), 814 parameters, no restraints. Lp and absorption corrections applied, $\mu=0.095 \mathrm{~mm}^{-1}$. Cocrystal 4: $\mathrm{C}_{66} \mathrm{H}_{80} \mathrm{O}_{18} \mathrm{~N}_{2}$, $M=1189.32$, pink prism, $a=12.6309(14) \AA, b=15.1204(17) \AA, c=16.9812(19) \AA$, $\alpha=80.807(1)^{\circ}, \beta=75.354(1)^{\circ}, \gamma=79.911(1)^{\circ}$, space group $P \overline{1}, V=3066.5(6) \AA^{3}$, $Z=2, D_{\mathrm{c}}=1.288 \mathrm{~g} \mathrm{~cm}^{-3}, F_{000}=1268$, Mo K $\alpha$ radiation, $\lambda=0.71073 \AA, T=173 \mathrm{~K}$, 13842 reflections collected. Final GooF $=1.035, R 1=0.059, \mathrm{w} R_{2}=0.157, R$ indices based on reflections with $I>2 \sigma(I)$ (refinement on $F^{2}$ ), 814 parameters, 42 restraints. Lp and absorption corrections applied, $\mu=0.093 \mathrm{~mm}^{-1}$. Cocrystal 5: $\mathrm{C}_{68} \mathrm{H}_{86} \mathrm{O}_{19} \mathrm{~N}_{2}, M=1235.39$, pink plate, $a=12.4659(7) \AA, b=15.6276(8) \AA, c=$ 17.6068(9) $\AA, \alpha=69.247(2)^{\circ}, \beta=75.581(3)^{\circ}, \gamma=78.539(3)^{\circ}$, space group $P \overline{1}, V=$ 3083.2(3) $\AA^{3}, Z=2, D_{\mathrm{c}}=1.331 \mathrm{~g} \mathrm{~cm}^{-3}, F_{000}=1320$, CuK $\alpha$ radiation, $\lambda=1.54178$ $\AA, T=173 \mathrm{~K}, 10079$ reflections collected. Final GooF $=1.031, R_{1}=0.058, \mathrm{w} R_{2}=$ $0.160, R$ indices based on reflections with $I>2 \sigma(I)$ (refinement on $F^{2}$ ), 848 parameters, no restraints. Lp and absorption corrections applied, $\mu=0.797$ $\mathrm{mm}^{-1}$. Cocrystal 6: $\mathrm{C}_{72} \mathrm{H}_{94} \mathrm{O}_{19} \mathrm{~N}_{2}, M=1291.49$, pink prism, $a=12.407(3) \AA, b=$ 15.969(3) ̊, $c=18.498(4) \AA, \alpha=79.532(3)^{\circ}, \beta=71.722(3)^{\circ}, \gamma=80.076(3)^{\circ}$, space group $P \overline{1}, V=3396.0(12) \AA^{3}, Z=2, D_{\mathrm{c}}=1.263 \mathrm{~g} \mathrm{~cm}^{-3}, F_{000}=1384$, Mo K $\alpha$ radiation, $\lambda=0.71073 \AA, T=173 \mathrm{~K}, 15307$ reflections collected. Final GooF $=$ 1.046, $R_{1}=0.083, \mathrm{w} R_{2}=0.240, R$ indices based on reflections with $I>2 \sigma(I)$ (refinement on $F^{2}$ ), 930 parameters, 87 restraints. Lp and absorption corrections applied, $\mu=0.091 \mathrm{~mm}^{-1}$. Cocrystal 7: $\mathrm{C}_{71} \mathrm{H}_{90.25} \mathrm{O}_{18.5} \mathrm{~N}_{2}, M=1267.70$, pink plate, $a=33.748(4) \AA, b=12.5218(13) \AA, c=31.831(3) \AA, \alpha=90^{\circ}, \beta=102.816(1)^{\circ}, \gamma=$ $90^{\circ}$, space group $C 2 / c, V=13116(2) \AA^{3}, Z=8, D_{\mathrm{c}}=1.284 \mathrm{~g} \mathrm{~cm}^{-3}, F_{000}=5426$, Mo $\mathrm{K} \alpha$ radiation, $\lambda=0.71073 \AA, T=173 \mathrm{~K}, 14495$ reflections collected. Final $\mathrm{GooF}=$ 1.039, $R_{1}=0.058, \mathrm{w} R_{2}=0.158, R$ indices based on reflections with $I>2 \sigma(I)$ (refinement on $F^{2}$ ), 874 parameters, 26 restraints. Lp and absorption corrections applied, $\mu=0.092 \mathrm{~mm}^{-1}$. Cocrystal 8: $\mathrm{C}_{69} \mathrm{H}_{84.5} \mathrm{O}_{17.5} \mathrm{~N}_{2.5}, M=1228.89$, pink plate, $a=33.339(11) \AA, b=12.549(4) \AA, c=31.947(11) \AA, \alpha=90^{\circ}, \beta=105.020(5)^{\circ}, \gamma=$ $90^{\circ}$, space group $C 2 / c, V=12909(8) \AA^{3}, Z=8, D_{\mathrm{c}}=1.265 \mathrm{~g} \mathrm{~cm}^{-3}, F_{000}=5248$, Mo K $\alpha$ radiation, $\lambda=0.71073 \AA, T=173 \mathrm{~K}, 6755$ reflections collected. Final GooF $=$ 1.057, $R_{1}=0.084, \mathrm{w} R_{2}=0.236, R$ indices based on reflections with $I>2 \sigma(I)$ (refinement on $F^{2}$ ), 839 parameters, 36 restraints. Lp and absorption corrections applied, $\mu=0.091 \mathrm{~mm}^{-1}$.

\section{Acknowledgements}

JLA thanks the NSF for funding this work.

\section{Notes and references}

1 (a) M. Busi, M. Laurenti, G. G. Condorelli, A. Motta, M. Favazza, I. L. Fragalà, M. Montalti, L. Prodi and E. Dalcanale, Chem. - Eur. J., 2007, 13, 6891-6898; (b) S. J. Dalgarno, J. Antesberger, R. M. McKinlay and J. L. Atwood, Chem. - Eur. J., 2007, 13, 8248-8255; (c) S. J. Dalgarno, G. W. V. Cave and J. L. Atwood, Angew. Chem., Int. Ed., 2006, 45, 570-574; (d) O. V. Kulikov, M. M. Daschbach, C. R. Yamnitz, N. Rath and G. W. Gokel, Chem. Commun., 2009, 7497-7499; (e) R. Pinalli, V. Cristini, V. Sottili, S. Geremia, M. Campagnolo, A. Caneschi and E. Dalcanale, J. Am. Chem. Soc., 2004, 126, 6516-6517.

2 (a) J. L. Atwood, E. K. Brechin, S. J. Dalgarno, R. Inglis, L. F. Jones, A. Mossine, M. J. Paterson, N. P. Power and S. J. Teat, Chem. Commun., 2010, 46, 3484-3486; (b) S. J. Dalgarno, N. P. Power, J. E. Warren and J. L. Atwood, Chem. Commun., 2008, 1539-1541; (c) S. J. Dalgarno, N. P. Power and J. L. Atwood, Coord. Chem. Rev., 2008, 252, 825-841; (d) S. J. Dalgarno, N. P. Power, J. E. Warren and J. L. Atwood, Chem. Commun., 2008, 1539; (e) P. Jin, S. J. Dalgarno and J. L. Atwood, Coord. Chem. Rev., 2010, 254, 1760-1768; $(f)$ P. Jin, S. J. Dalgarno, J. E. Warren, S. J. Teat and J. L. Atwood, Chem. Commun., 2009, 3348-3350; (g) R. M. McKinlay, G. W. V. Cave and J. L. Atwood, Proc. Natl. Acad. Sci. U. S. A., 2005, 102, 5944-5948; (h) R. M. McKinlay, P. K. Thallapally and J. L. Atwood, Chem. Commun., 2006, 2956-2958; (i) R. M. McKinlay, P. K. Thallapally, G. W. V. Cave and J. L. Atwood, Angew. Chem., Int. Ed., 2005, 44, 5733-5736; (j) N. Power, S. J. Dalgarno and J. L. Atwood, Angew. Chem., Int. Ed., 2007, 46, 8601-8604.

3 (a) A. V. Mossine, H. Kumari, D. A. Fowler, A. K. Maerz, S. R. Kline, C. L. Barnes and J. L. Atwood, Isr. J. Chem., 2011, 51, 840-842; (b) A. V. Mossine, H. Kumari, D. A. Fowler, A. Shih, S. R. Kline, C. L. Barnes and J. L. Atwood, Chem. - Eur. J., 2012, 18, 10258-10260.

4 (a) D. A. Fowler, J. Tian, C. Barnes, S. J. Teat and J. L. Atwood, CrystEngComm, 2011, 13, 1446; (b) D. A. Fowler, J. Tian, C. Barnes, S. J. Teat and J. L. Atwood, CrystEngComm, 2011, 13, 1446-1449; (c) H. Kumari, J. Zhang, L. Erra, L. J. Barbour, C. A. Deakyne and J. L. Atwood, CrystEngComm, 2013, 15, 4045-4048.

5 (a) D. A. Fowler, S. J. Teat, G. A. Baker and J. L. Atwood, Chem. Commun., 2012, 48, 5262-5264; (b) D. A. Fowler, C. R. Pfeiffer, S. J. Teat, C. M. Beavers, G. A. Baker and J. L. Atwood, CrystEngComm, 2014, 6010-6022; (c) D. A. Fowler, J. L. Atwood and G. A. Baker, Chem. Commun., 2013, 49, 1802-1804; (d) D. A. Fowler, C. R. Pfeiffer, S. J. Teat, G. A. Baker and J. L. Atwood, Cryst. Growth Des., 2014, 14, 4199-4204.

6 (a) K. K. Kline, D. A. Fowler, S. A. Tucker and J. L. Atwood, Chem. - Eur. J., 2011, 10848; (b) S. J. Dalgarno, S. A. Tucker, 
D. B. Bassil and J. L. Atwood, Science, 2005, 309, 2037-2039; (c) S. J. Dalgarno, D. B. Bassil, S. A. Tucker and J. L. Atwood, Angew. Chem., Int. Ed., 2006, 45, 7019-7022; (d) D. B. Bassil, S. J. Dalgarno, G. W. V. Cave, J. L. Atwood and S. A. Tucker, J. Phys. Chem., 2007, 111, 9088-9092.

7 E. S. Barrett, T. J. Dale and J. Rebek Jr., J. Am. Chem. Soc., 2007, 129, 3818-3819.

8 (a) C. R. Pfeiffer, D. A. Fowler and J. L. Atwood, Cryst. Growth Des., 2014, 14, 4205-4213; (b) C. R. Pfeiffer, D. A.
Fowler, S. J. Teat and J. L. Atwood, CrystEngComm, 2014, 16, 10760-10773; (c) C. R. Pfeiffer, S. G. Atwood, L. Samadello and J. L. Atwood, Cryst. Growth Des., 2015, DOI: 10.1021/acs. cgd.5b00385.

9 P. Bombicz, T. Gruber, C. Fischer, E. Weber and A. Kalman, CrystEngComm, 2014, 16, 3646-3654.

10 T. Gerkensmeier, W. Iwanek, C. Agena, R. Fröhlich, S. Kotila, C. Näther and J. Mattay, Eur. J. Org. Chem., 1999, 1999, 2257-2262. 